\title{
La necrópolis medieval del Cerro de La Horca en Toledo
}

\author{
Arturo Ruiz Taboada *
}

La excavación arqueológica desarrollada en un sector del Cerro de La Horca ha permitido conocer aspectos inéditos del ritual de enterramiento medieval en Toledo. Se ha documentado una amplia tipología de tumbas con un único elemento constructivo común para todas ellas, la excavación previa de una fosa que, en numerosos casos, alcanza gran profundidad. El desconocimiento sobre el mundo funerario medieval toledano y la falta de materiales arqueológicos representativos en esta necrópolis han obligado a reflexionar sobre la comunidad religiosa a la que pertenecen estos enterramientos. Por fuentes históricas y excavaciones previas, conocemos la localización de necrópolis musulmanas y cristianas. La localización de la(s) judía(s) había sido, al menos hasta ahora, una incógnita.

PalABras Clave: Toledo; Cerro de La Horca; patrones funerarios; arqueología medieval.

The Medieval Necropolis of the Cerro de la Horca in Toledo.-The archaeological excavation of part of a medieval necropolis at the Cerro de la Horca (Toledo) has provided new information regarding burial traditions in Toledo. One formal aspect is common to the broad range of graves that have been brought to light, namely the pit that was dug for the burial, being of considerable depth in a number of cases. Because little is known of the funerary practices in Toledo during the Middle Ages and hardly any objects have been recovered in the excavation, it is difficult to identify the religious community to which it belonged. Whereas the location of Muslim and Christian cemeteries have been known through documentary and archaeological sources, only popular traditions quoted so far the Jewish necropolis, its location remaining thus a mystery.

Keywords: Toledo; ‘Cerro de La Horca;' Necropolis; Burial Patterns; Medieval Archaeology.

La dilatada historia de Toledo ha favorecido que proliferen extramuros cementerios de todas las épocas, desde la necrópolis clásica, al noreste del circo romano, a los cementerios tardorromano y visigodo, de Vega Baja y su entorno. En la Edad Media, estos cementerios se localizan frente a las puertas o junto a los caminos principales. Son conocidos los cristianos bajo la puerta del Cambrón, en el entorno de Santa Leocadia de Afuera, los musulmanes frente a la Puerta Antigua de Bisagra, en el Circo Romano, junto a la ermita de San Eugenio y,

\footnotetext{
*taboada@arrakis.es
} 
recientemente, también se han descubierto enterramientos junto a la Puerta del Vado. Los cementerios judíos se han venido tradicionalmente asociando con el Pradillo de San Bartolomé, también junto al Circo Romano, y con el Cerro de La Horca (Fig. 1). De la identificación actual de todos ellos, tenemos únicamente evidencia arqueológica de cristianos y musulmanes. Por el contrario, sólo se tiene constancia funeraria judía a partir de textos poco precisos y noticias aisladas. La labor de excavación en la necrópolis del Cerro de la Horca puede ayudar en un futuro a la identificación y catalogación de este tipo de enterramientos, no sólo en Toledo sino en el resto de la Península Ibérica.

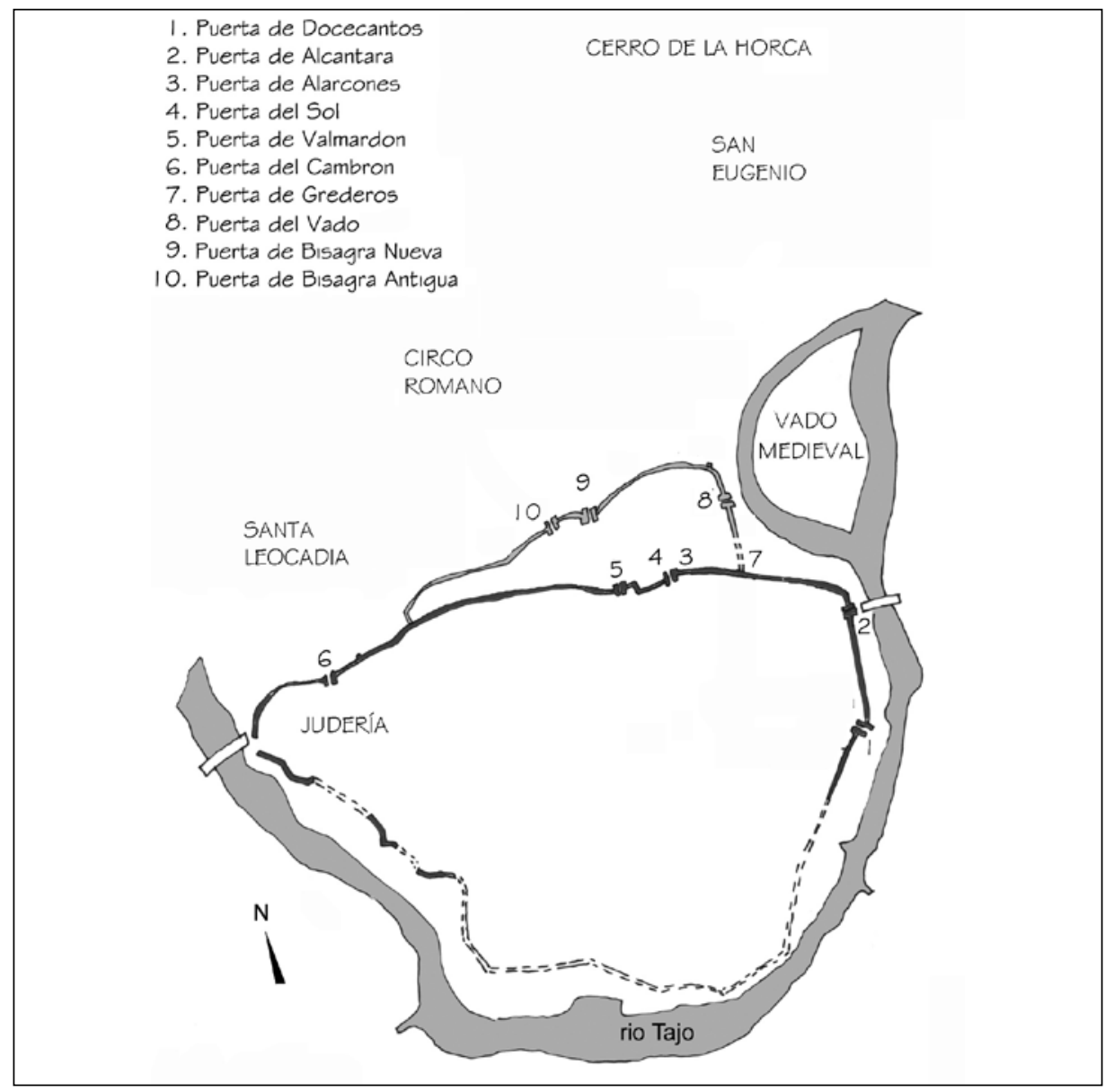

Fig. 1. Plano de situación de la necrópolis del Cerro de La Horca en el conjunto extramuros de la ciudad. 


\section{Los enterramientos del Cerro de la Horca.}

En una superficie de 300 metros cuadrados se han documentado un total de 107 tumbas dispuestas en diferentes filas orientadas de norte a sur. La excavación arqueológica de que nos ocupamos en este artículo se encuadra en las obras de ampliación del Instituto de Educación Secundaria Azarquiel de Toledo ${ }^{1}$. Los trabajos arqueológicos desarrollados entre los años 2008 y 2009 se han limitado al área afectada por las obras, aunque se ha podido constatar que esta necrópolis tiene continuidad por el resto de la ladera (Figs. 2 y 3 ).

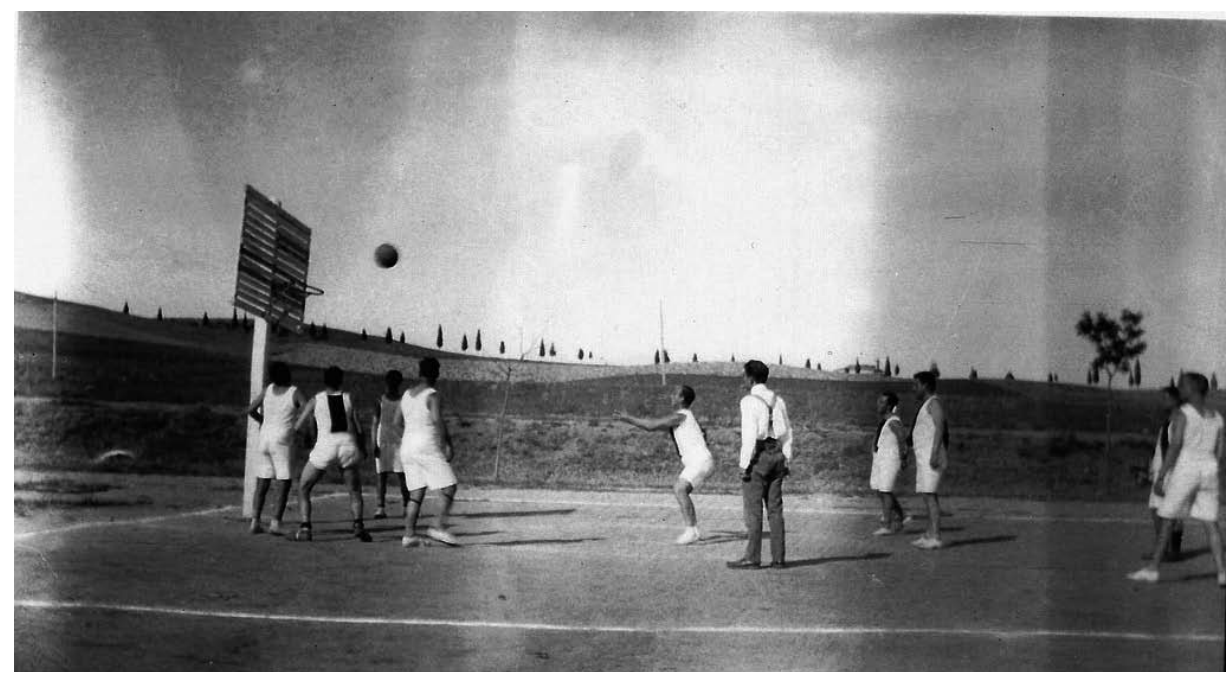

Fig. 2. Vista de la ladera del Cerro de la Horca (mediados del siglo XX), con los cipreses recién plantados, desde los llamados «Campos de Don Gregorio» (@) Archivo Provincial de Toledo).

${ }^{1}$ En la excavación han participado como arqueólogos, Beatriz Martín Eguiguren, María Teresa Fernández Montoya, Nuria López San Juan, Beatriz Antelo, Sandra Azcárraga, Eva María Rodríguez, Elena Martínez, así como dos antropólogas, Helena Coscollano y Berta Martínez, a cargo de Armando González, de la Universidad Autónoma de Madrid. La excavación arqueológica fue financiada por la Delegación de Educación de la Junta de Comunidades de Castilla-La Mancha, propietaria del Instituto. En agosto del año 2008 se iniciaron unos sondeos previos en el área afectada por las obras de ampliación del centro educativo que se debían llevar a cabo, en cumplimiento del artículo 21 de la Ley de Patrimonio Histórico de Castilla-La Mancha. En estos sondeos se identifican las delimitaciones superficiales de algunos enterramientos. Una vez solicitado el permiso correspondiente a la Dirección General de Patrimonio Cultural de la Junta para la excavación en área de la superficie afectada por las obras, las excavaciones tuvieron lugar entre septiembre de 2008 y enero de 2009. 


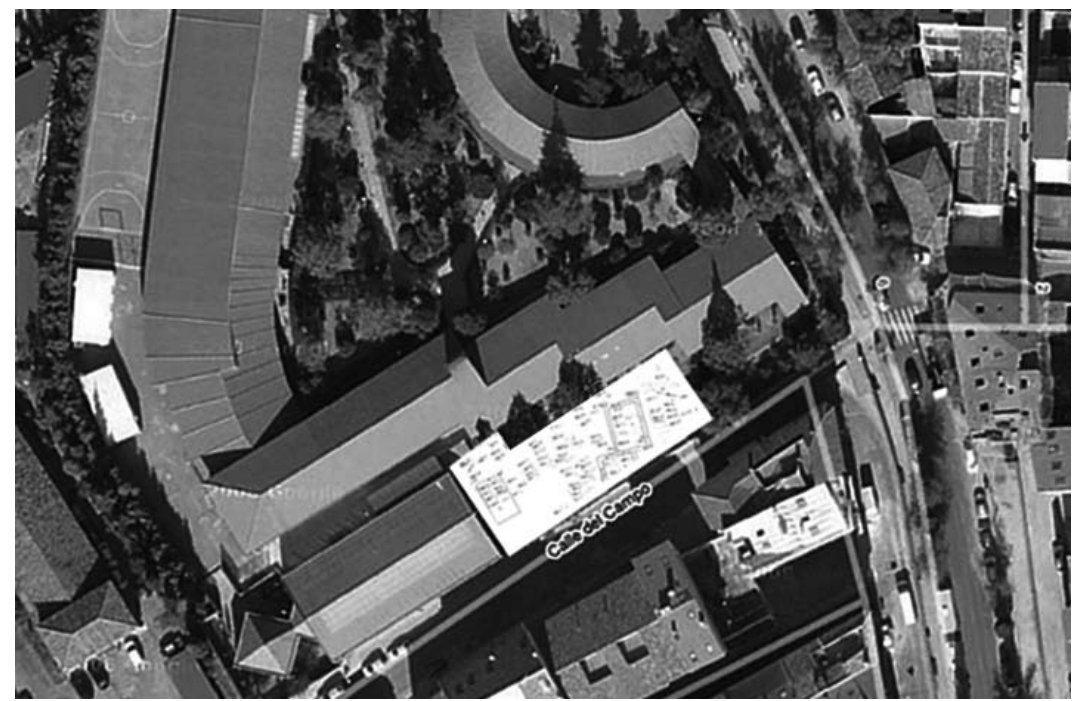

Fig. 3. Localización de la zona excavada dentro del IES Azarquiel de Toledo.

La localización de la necrópolis en el Cerro de La Horca apunta, de entrada, a su identificación con uno de los cementerios judíos toledanos. De hecho, las fuentes históricas mencionan dos lugares de enterramiento de la comunidad judía extramuros de la ciudad: El Pradillo de San Bartolomé (en torno al circo romano) y el Cerro de La Horca ${ }^{2}$. De estas dos necrópolis se desconoce tanto su extensión como su ubicación exacta, aunque tenemos constancia material de su existencia por la colección de lápidas monolíticas con inscripciones, dispersas por toda la ciudad, bien en museos o formando parte de las cimentaciones de algunos monumentos góticos.

La excavación se localiza en un pequeño sector de la ladera oeste del Cerro de La Horca. El hecho de que a escasos metros al Este se encuentren los límites de otro cementerio, en este caso de origen taifa (junto a San Eugenio), dificulta, aún más, la interpretación de los restos aparecidos. De este cementerio Taifa tenemos noticias por fuentes históricas y por las excavaciones llevadas a cabo a principios del siglo pasado por Amador de los Ríos, aunque en fechas más recientes, se han localizado enterramientos en el entorno de la ermita de San

${ }^{2}$ El Pradillo de San Bartolomé toma su nombre del convento de San Bartolomé, localizado a los pies del Circo Romano y que ya dibujara El Greco en su obra «Vista y Plano de Toledo». Por otro lado y en espera de los datos que en un futuro pueda aportar el estudio de las fuentes históricas, la existencia del cementerio en este lugar la recoge P. León TelLo, Judíos de Toledo (Madrid 1979), tomo I, pág. 272. 
Eugenio, adscritos a ese mismo entorno ${ }^{3}$. Por el contrario, en el Cerro de La Horca las numerosas obras públicas que se han desarrollado en su vertiente suroeste a partir de la década de los setenta del siglo pasado, han sacado a la luz un gran número de enterramientos abarcando una amplia superficie de terreno ${ }^{4}$.

La identificación arqueológica de la necrópolis del Pradillo de San Bartolomé en el Circo Romano es aún más compleja. La mayoría de los datos provenientes de las excavaciones arqueológicas en este lugar no han sido publicados, y los que sí lo han sido, interpretan los restos aparecidos como musulmanes. A este respecto, en un reciente artículo, Ruiz Taboada y Martín han cuestionado la interpretación que se hace del ritual de enterramiento en esta zona, al considerar que la zona puede albergar enterramientos de distintas religiones y proponer nuevas vías de investigación para futuros trabajos en ese entorno ${ }^{5}$.

Pero volviendo a la necrópolis medieval descubierta, su patrón de enterramiento se caracteriza por el uso de fosas simples para depositar el ataúd, con o sin estructura arquitectónica asociada (Fig. 4). No se han documentado casos de enterramientos en fosas con covacha lateral, como ocurre en Barcelona, Gerona o Lucena, y sí un complejo sistema constructivo que acompaña a las tumbas del que luego hablaremos, similar al de Sevilla. Estas fosas se encuentran excavadas en el alcaén (o sustrato geológico local), tienden a tener planta trapezoidal y se han identificado dos tipologías distintas que tienen que ver con su tamaño y el número de individuos para el que fueron excavadas: fosas individuales y fosas que albergan enterramientos separados de varios individuos. Estas últimas, aunque menos abundantes, pueden albergar hasta tres cuerpos. El sistema constructivo de cada tumba contenida en estas amplias fosas hace que los enterramientos conserven en todo momento la condición de individuales. Otro detalle significativo es la gran profundidad que pueden llegar a alcanzar las fosas. Exceptuando casos aislados en los que los individuos aparecían a escasos centímetros de la superficie, la profundidad de estas fosas oscila entre los $60 \mathrm{~cm}$ y los dos metros y medio, siendo la

${ }^{3}$ E. Domínguez Fernández, «La necrópolis judía en torno a la ermita de San Eugenio», en P. Atoche, C. Rodriguez \& M. ${ }^{a}$ A. Ramirez (eds.), Mummies and Science: World Mummies Research (Santa Cruz 2008), págs. 213-218.

${ }^{4}$ Por desgracia no existe documentación arqueológica de estos hallazgos y sí crónicas escritas de su destrucción; cf. J. GómEz MENOR «Algunos datos sobre el cementerio judío de Toledo», Sef 31 (1971), págs. 367-373; A. M. ${ }^{a}$ LóPEz Álvarez, «Nuevas noticias sobre el cementerio judío de Toledo» Sef 39 (1979), págs. 120-122. Hoy en día, el Cerro de La Horca se encuentra totalmente urbanizado y sobre él se localiza uno de los barrios que conforman la periferia de la ciudad.

5 «La identificación de enterramientos judíos en el contexto funerario medieval de Toledo», en Actas. Congreso de Arqueología Medieval en la Península Ibérica (Murcia 2009, en preparación). 


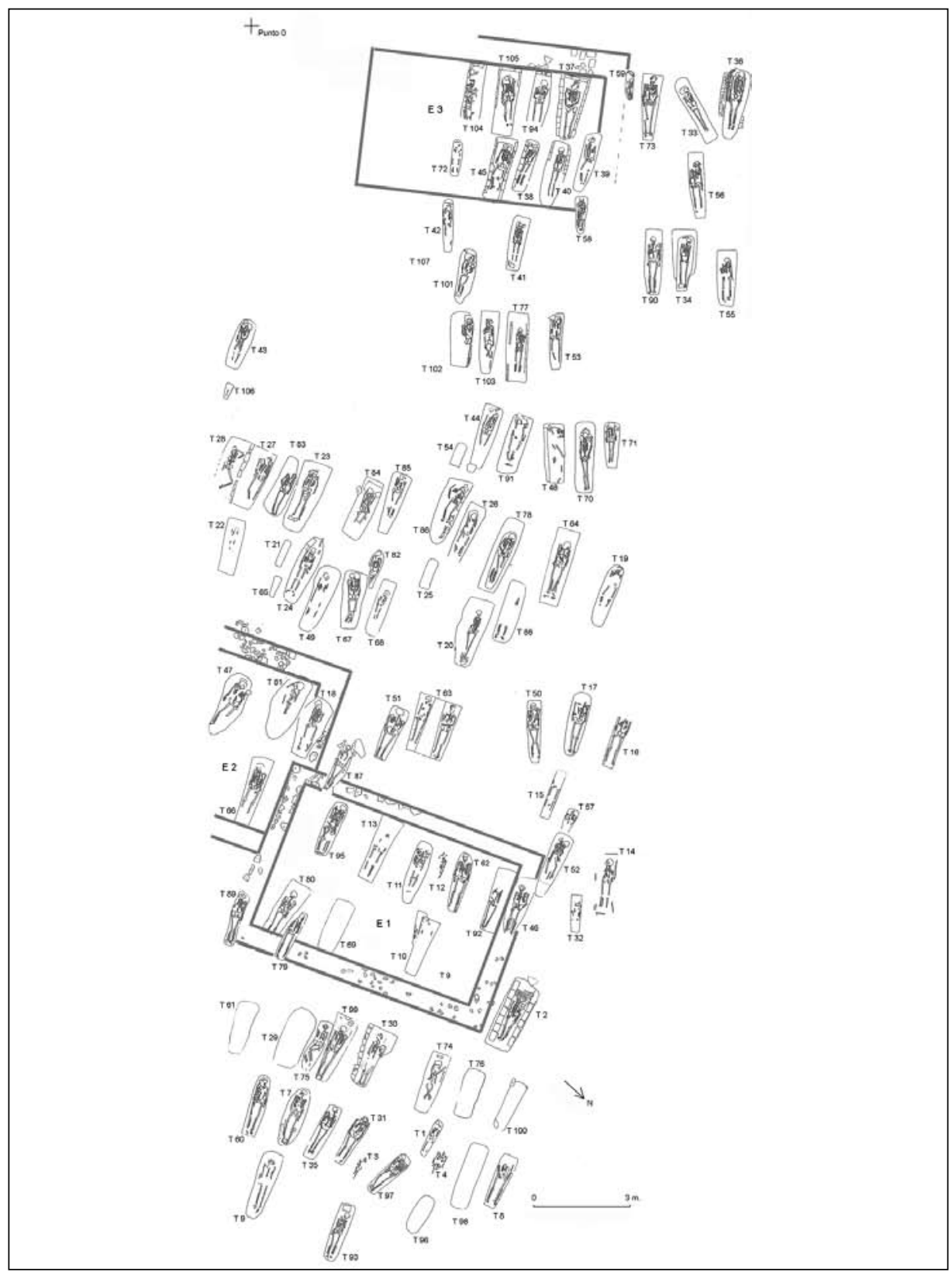

Fig. 4. Planta general de la parcela de la necrópolis. 
tumba 85 la más llamativa por el tipo de excavación de la fosa, de planta trapezoidal, y por su gran profundidad (2,50 m) (Fig. 5).

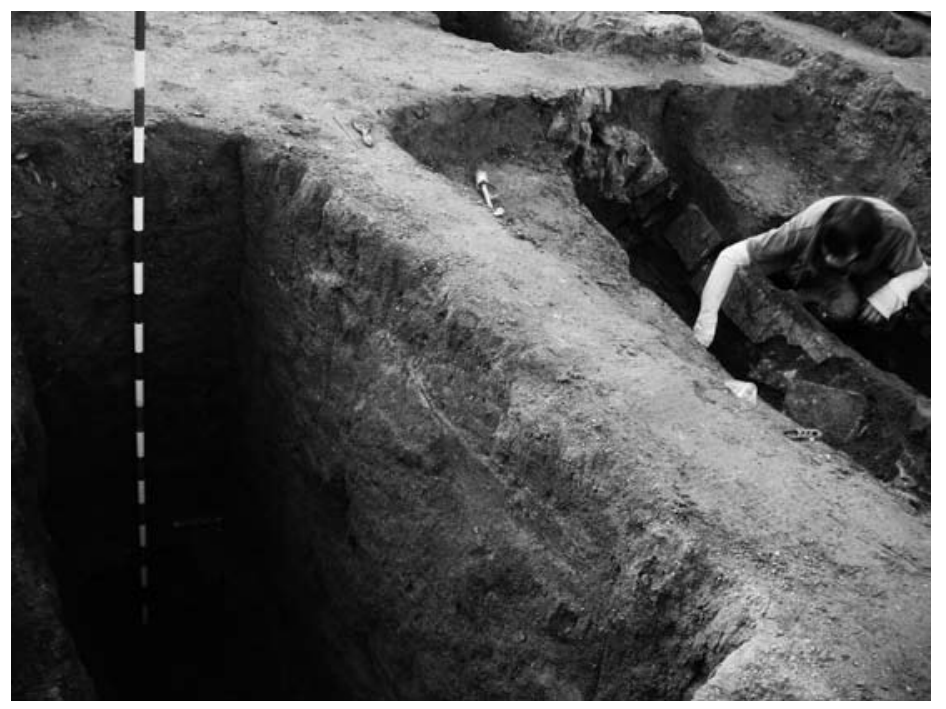

Fig. 5. Detalle de la fosa de la Tumba 85 .

El paso siguiente a la excavación de la fosa es la construcción de la tumba para albergar el cuerpo. En este caso, las tumbas pueden dividirse genéricamente en dos categorías: con o sin estructura arquitectónica asociada. En ambos casos la colocación del cuerpo siempre es la misma, dentro del ataúd sobre suelo virgen. Posteriormente se procede al relleno de la fosa. En los casos de las tumbas sin estructura, este relleno se hace con la misma tierra derivada de su excavación previa. También se ha documentado de forma generalizada la delimitación del ataúd y su afianzo bien con ladrillos o con mampuestos de mediano tamaño. En algunos casos, dicha delimitación intermedia se ha documentado dentro de los lucillos. En el momento de la exhumación de los cuerpos, estos materiales aparecen sobre los restos de madera de la tapa de los ataúdes, y en los casos en los que no se conserva, integrados en el desarrollo del esqueleto.

En las tumbas con estructura, el proceso se complica al incorporar una bóveda de ladrillo sobre el ataúd. Esta bóveda de ladrillo o lucillo, generalmente de planta trapezoidal, puede estar cimentada sobre paredes de ladrillo, y con testeros delimitando sus extremos. La otra variedad documentada es la bóveda que se apoya directamente en las paredes de alcaén, tras su acondicionamiento para tal efecto (sirva también como ejemplo la tumba 85). 
La construcción de la bóveda de cierre se hace en el momento en el que el ataúd se encuentra depositado en el fondo de la tumba, pues si no sería imposible su introducción una vez terminada. Basándose en este hecho, se descarta la interpretación que otros autores han hecho del modo de enterramiento en estructuras parecidas de Toledo o Sevilla ${ }^{6}$. Una vez acabada la bóveda, las fosas se colmatarían con la misma tierra proveniente de su excavación, y como ocurriría en el caso anterior, desprovista de material arqueológico alguno. No se ha documentado registro material significativo, salvo la propia tipología de las tumbas y sus restos humanos, o escasos fragmentos diminutos de cerámica.

Hasta este momento, y a partir de hallazgos aislados, se ha dado por supuesto que el uso del lucillo era común en las tres religiones existentes en la ciudad de Toledo. Un análisis del registro arqueológico plantea dudas interpretativas a este respecto, o bien demuestra lo contrario. En el caso de las necrópolis cristianas, tanto extramuros como intramuros, acerca de las que se han publicado noticias de su excavación (San Andrés, San Lorenzo, el Cristo de la Luz, San Bartolomé o Santa Leocadia de Afuera), se ha constatado la ausencia generalizada de lucillos en favor de otras tipologías constructivas ${ }^{7}$. En la única necrópolis en la que aparecen lucillos asociados con enterramientos islámicos es en el Circo Romano que, como hemos visto, presenta problemas de interpretación.

Hasta que no se demuestre lo contrario, el cierre subterráneo de la tumba mediante la construcción de una bóveda o lucillo está relacionado con un ritual de enterramiento diferente al musulmán y al cristiano. Para ellos, la orientación de la cabeza es determinante en la inhumación: hacia el este para musulmanes, al cielo para cristianos. Estos últimos, para evitar que, tras la esqueletización del cuerpo, la cabeza caiga a ambos lados, tienden a antropomorfizar las fosas y fábricas de las tumbas. En los cuerpos del Cerro de La Horca, la cabeza descansa sobre una almohadilla, sin que existan indicios de haber sido intencionadamente sujeta.

${ }^{6}$ A. DE JuAn en su libro Los enterramientos musulmanes del Circo Romano de Toledo (Toledo 1987), págs. 52-53, identifica la existencia de una pequeña fosa delante de la cabecera de algunos lucillos, que interpreta como un rehundimiento del terreno para facilitar la entrada del ataúd en la bóveda. Para este autor, el lucillo estaría construido antes de la inhumación del cadáver. Algo similar interpreta Guijo Mauri, que considera que los lucillos se cierran provisionalmente en sus extremos con ladrillos o pequeñas piedras, cierre que se elimina al introducir el ataúd (cf. J. M. GuiJo MAURI, «Inhumaciones de grupos marginales en Sevilla. La minoría hebrea», Archeologia Medievale 28 (2001), págs. 373-381.

${ }^{7}$ C. Delgado, Arte Hispano Musulmán: Artículos (Madrid 2001); A. Ruiz Taboada, «San Andrés y San Bartolomé: Torres campanario en el Toledo de Reconquista», en Alminares y torres. Herencia y presencia del Toledo Medieval [= Los Monográficos del Consorcio 4] (Toledo 2008). 
Común para ambos tipos de fosa debió ser el sistema de delimitación superficial de las tumbas. Aunque en muchos de los casos se ha perdido, contamos con algún ejemplo como el de las tumbas 2 o 14. La primera es muy interesante al poseer un suelo espigado de planta rectangular, coincidiendo con el lucillo que se encuentra bajo tierra ${ }^{8}$. Por el contrario, la tumba 14 posee una estructura más simple a base de ladrillos colocados en sardinel describiendo el rectángulo de la tumba, y un relleno de piedras de mediano tamaño en su interior. En ambos casos no se descarta que un monolito en piedra de forma rectangular y sección troncopiramidal señalara la tumba en superficie. Por desgracia, se sabe por las fuentes escritas que fueron los monarcas los que autorizaron a comienzos del siglo XVI la venta de estos monolitos de piedra a diferentes canteros toledanos para su reutilización en edificios góticos en construcción. Algunos de ellos se pueden contemplar en distintos monumentos repartidos por la ciudad ${ }^{9}$.

La colocación y orientación de los individuos es siempre la misma, aunque con excepciones. Aparecen en decúbito supino con los brazos extendidos pegados al cuerpo y las manos en línea, aunque pueden tener una mano o las dos sobre la pelvis. Los pies se disponen cruzados, paralelos o enfrentados, con los talones en los extremos. La cabeza mira al cielo y, en la mayoría de los casos, reposa sobre una almohadilla con base de arcilla de color verdoso o grisáceo. La orientación de los cuerpos generalmente es de noroeste-sureste, aunque conviene destacar como excepciones las tumbas 33 y 97, orientadas de sur a norte y de oeste a este respectivamente. Este hecho responde más al intento de no alterar o dañar alguna tumba preexistente que a un ritual de enterramiento concreto. Este empeño puede llegar al extremo de alterar la tipología de la bóveda. Cuando los artesanos alarifes excavaban la tumba 86 se encuentran con que esta puede da-

${ }^{8}$ En este caso, De Juan, Los enterramientos musulmanes, págs. 53-54 sí identifica esta tipología de tumba, caracterizada por lucillos, de planta trapezoidal, simples o dobles. Estos se encontraban cubiertos de tierra desprovista de material arqueológico y, a su vez, delimitados en superficie por estructuras de ladrillo o piedra de planta rectangular. Bajo estas estructuras se localizaba el ataúd, de forma trapezoidal, directamente colocado sobre la tierra. Dentro del ataúd se depositaba al individuo, en decúbito supino, con los brazos extendidos y las manos sobre los coxales. Las piernas se encontraban estiradas y el cráneo mirando de frente o hacia el sureste. La cabeza en muchas ocasiones descansaba sobre una almohadilla formada a base de tierra de color cenicienta. Ninguna de las tumbas contenía ajuar, salvo excepciones poco representativas. Este autor no descarta que pudieran ser tumbas mudéjares.

${ }^{9}$ Gómez Menor, «Algunos datos sobre el cementerio judío», pág. 368, documenta el caso del arquitecto Enrique Egas, uno de los posibles compradores en 1508 de estos monolitos. Aunque el documento habla del fonssario de los judíos, hoy es imposible saber a cuál de los dos existentes en la ciudad se refería. Una de estas lápidas dedicada a Yosef Elnacave se puede contemplar en la portada de la casa llamada «Corral de Don Diego», junto a Zocodover. 
ñar la cabecera de la tumba 26. Para evitar esto, el sepulturero rectifica tanto el trazado de la fosa como la forma del lucillo, al que le dota de un aspecto curvo.

Los enterramientos se encuentran desprovistos de ajuar ${ }^{10}$. El único material asociado a los cuerpos es la madera de los ataúdes, que en la mayoría de los casos se conserva en grandes cantidades ${ }^{11}$. De algunos ataúdes se ha podido recuperar tanto los clavos, como las argollas laterales empleadas para el transporte del ataúd. Este dato, aunque pueda parecer anecdótico, hace reflexionar sobre el uso generalizado o no de sudarios para transportar los cadáveres y en el papel de los ataúdes. Los estudios antropológicos que se han podido realizar in situ muestran que, si bien la deposición de alguno de los huesos puede indicar el uso de sudarios, en general, el cuerpo ha debido reposar desde un primer momento dentro del ataúd.

Por último, la amplia muestra de alteraciones postdeposicionales documentadas en 28 de las 107 tumbas nos permite comentar y cuestionar alguno de los tópicos esgrimidos sobre la preparación del cadáver y la identificación religiosa de una sepultura ${ }^{12}$. Hay que partir de la base que el esqueleto ha permanecido en hueco una serie de años hasta el colapso posterior de la estructura que lo encierra y su colmatación de tierra. Aun así, en algunas tumbas se ha encontrado el cadáver sin tierra al estar protegido por el lucillo. Esto ha permitido comprobar que el esqueleto presentaba alteraciones imposibles de sus extremidades, desde leves cambios en la orientación de los cráneos, hasta desplazamientos más evidentes con respecto al cuerpo, como tibias cruzadas o huesos en posición secundaria. De igual forma, se ha documentado un alto nivel de huesos revueltos en el interior de algunos lucillos, lo que nos lleva a pensar en la incidencia de roedores o pequeños mamíferos en el interior de las tumbas. Sin esta referencia, estas alteraciones podrían ser interpretadas como parte del ritual de enterramiento: desde la orientación de los cráneos (que, aunque por regla general miran al cielo, en alguno de estos casos los encontramos mirando al este o al oeste),

${ }^{10}$ Tan sólo se ha recogido un anillo de bronce con decoración geométrica en la tumba 40, un pendiente en la tumba 46 y una moneda en la tumba 101. Además, en las tumbas 12 y 40 aparecieron alfileres asociados al cráneo.

${ }^{11}$ Se han documentado clavos en 66 de las 107 tumbas, 45 de las cuales aún conservaban madera. En sólo un caso se ha documentado una fosa simple con una escasa muestra de huesos carbonizados, sin que hayamos sido capaces de dar ninguna explicación al respecto (tumba 76). Por último, sólo en un caso se ha documentado relleno de fosas con fragmentos de huesos humanos revueltos (tumba 50).

${ }^{12}$ Entre los más recurrentes se encuentra el fundamentar la identificación de la adscripción religiosa de la sepultura a partir de la orientación del cráneo o de la identificación de materiales ajenos al esqueleto y asociados a este como piedras o ladrillos. 
hasta la presencia de materiales (que en origen debieron ser ajenos a la colocación del cadáver, pero que al excavarlos nos los encontramos formando parte del enterramiento, como ladrillos, piedras o clavos).

\section{LA ORDENACIÓN DEL CEMENTERIO: LAS UNIDADES FAMILIARES}

El sector excavado se encuentra estructurado de tal forma que lo hace diferente del resto de necrópolis históricas toledanas conocidas hasta la fecha. Desde un punto de vista macroespacial, son varias las cuestiones que llaman la atención de este cementerio. De una parte, la ordenación de sus tumbas y la preocupación de no alterar los enterramientos más antiguos; esta ordenación se desarrolla a base de filas de fosas orientadas de noreste a suroeste. De otra, la compartimentación del espacio funerario, que en algunos casos hace que se localicen conjuntos de tumbas individuales dentro de estructuras cerradas de planta rectangular.

De entrada, la interpretación de estas compartimentaciones dentro del propio cementerio resulta compleja. No obstante, y dada la distribución y colocación de tumbas que se localizan en su interior, se las ha relacionado de manera hipotética con estructuras de tipo familiar. La distribución interna de estas estructuras puede responder a una división jerárquica de los miembros de una propia familia o clan ${ }^{13}$. La tradición funeraria judía procura la agrupación de familiares directos en un mismo lugar. Es de esperar que futuros trabajos de investigación basados en fuentes escritas, desconocidas o inéditas, puedan precisar y ejemplificar tal extremo. Por el momento, sólo se ha podido constatar este hecho en esta necrópolis. En este sentido y como veremos a continuación, las estructuras se ordenan en su interior y se compartimentan en dos filas, siendo las tumbas de mejor factura las que se colocan perpendiculares al muro oeste de cierre y, en torno a ellas, se distribuyen las demás.

Además de las interpretaciones que se puedan hacer sobre su uso y compartimentación interna, la excavación de las tumbas localizadas tanto en el interior como en el exterior de estas estructuras, ha permitido identificar levemente la existencia de una serie de fases de enterramiento. Pese a que en este tipo de cementerios la estratigrafía es horizontal, la existencia de tales superposiciones nos permite hablar de un uso continuo del espacio funerario a lo largo del tiempo. De las tres estructuras localizadas, sólo una se encuentra completa (E1) (Fig. 6).

La estructura 1 posee unas dimensiones de 8,40 x 5,20 m y una orientación similar al resto de filas documentadas en la necrópolis. Desde un punto de vista

${ }^{13}$ No se descarta que hubiera más estructuras que las tres documentadas, aunque no se hayan conservado. 


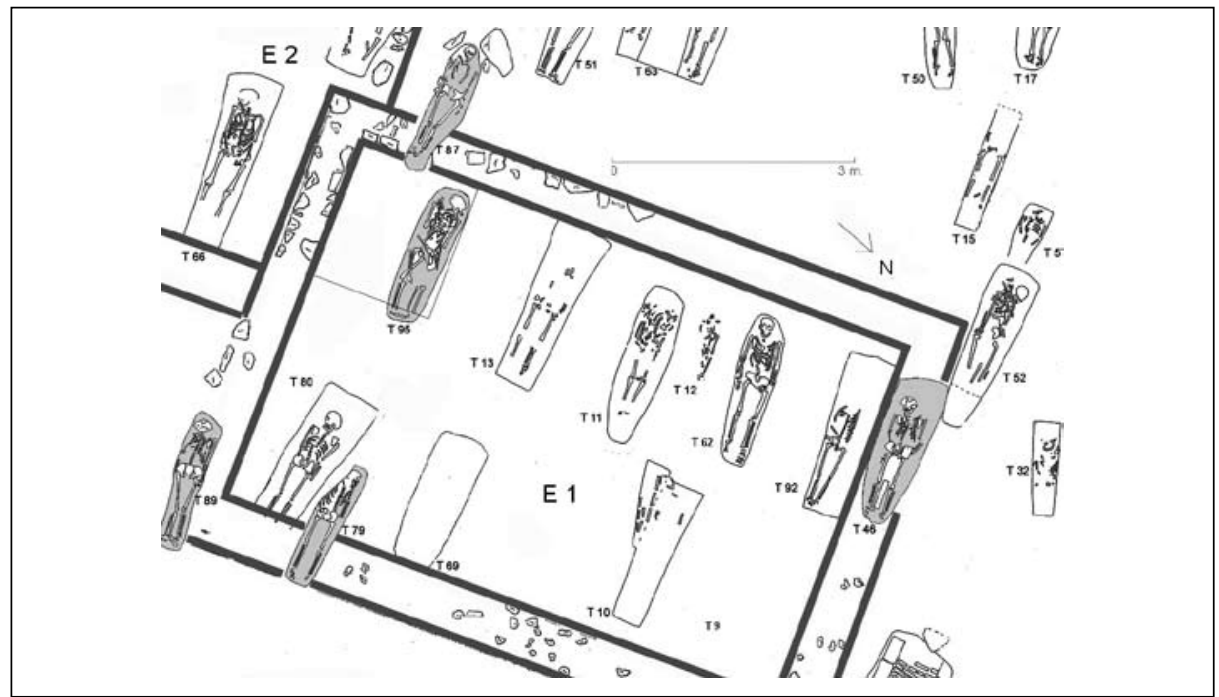

Fig. 6. Planta de la Estructura 1 y enterramientos asociados.

arquitectónico, la superficie está delimitada por un zócalo de mampostería en las partes en las que necesitan salvar el desnivel de la ladera y con un recrecido en tapial. De esta traza sólo se conserva un alzado que según los sitios oscila entre los 10 y los $20 \mathrm{~cm}$. Se ha identificado, a su vez, una segunda estructura más pequeña de planta cuadrada de 1,5 x 1,5 m, localizada en el ángulo suroeste, aunque no se ha podido establecer una funcionalidad concreta, al no poseer ni material asociado ni delimitar tumba alguna (Fig. 7).

La E1 posee 9 tumbas repartidas en dos filas y 5 más, que en algún momento rompen o son rotas por ella. La tumba 79 aparece cortada por la excavación de la fosa de la tumba 80 (coetánea a la estructura 1), lo que la convierte en la más antigua, mientras que las tumbas 46,89 y 95 , rompen la estructura 1, por lo que hay que considerarlas como más recientes. Todas estas tumbas no poseen lucillo.

En las estructuras 2 y 3 ocurre algo similar, aunque es en la 3 en la que mejor se aprecia. Desconocemos cuáles son las dimensiones de esta última, aunque por la distribución de las filas y su disposición frente al único muro que se conserva (el oeste), se puede deducir que sería similar a la E1 (Fig. 8). La estructura 3 además conserva parte del alzado de uno de los muros de cierre, no así el resto. Por su construcción sabemos que, al igual que ocurría con la estructura 1, el zócalo de cimentación del muro se hace de mampostería para salvar el desnivel de la ladera (Fig. 9). Este muro, de tradición mudéjar, está fabricado a base de cajones de mampostería separados por una verdugada simple de ladrillo. 


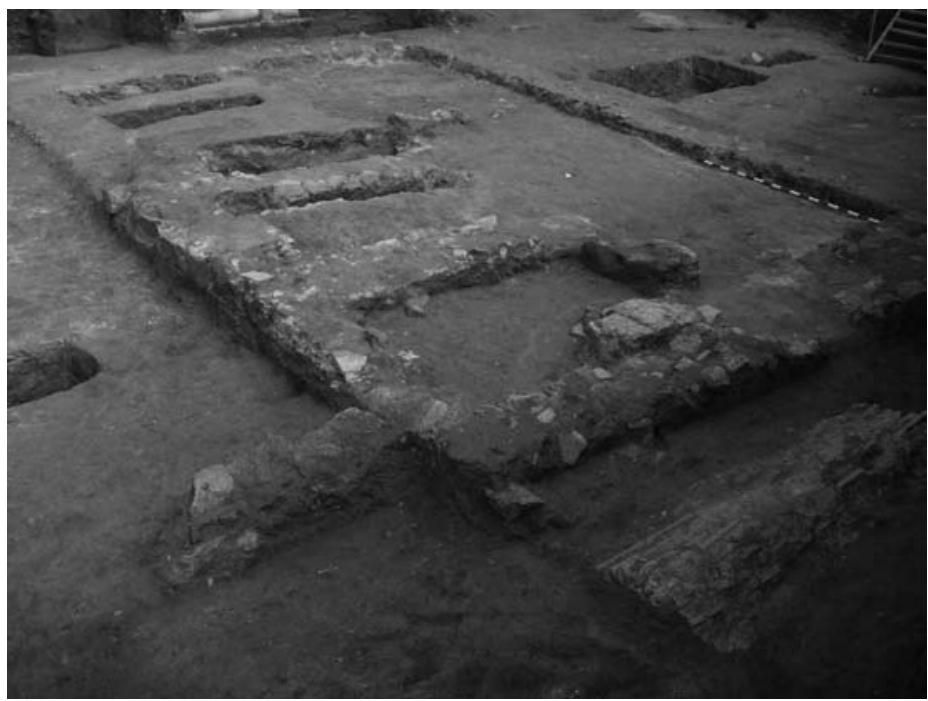

Fig. 7. Vista desde el sur de la Estructura 1 y del espacio rectangular situado al interior del ángulo sur oeste.

Es de suponer que, a una cierta altura, el zócalo de mampostería diera paso al tapial. En la sección de este muro se aprecia perfectamente tanto el diseño para salvar el desnivel como el remate de las tumbas asociadas al mismo. Tres de las tumbas documentadas en el interior de esta estructura son las mejor elaboradas

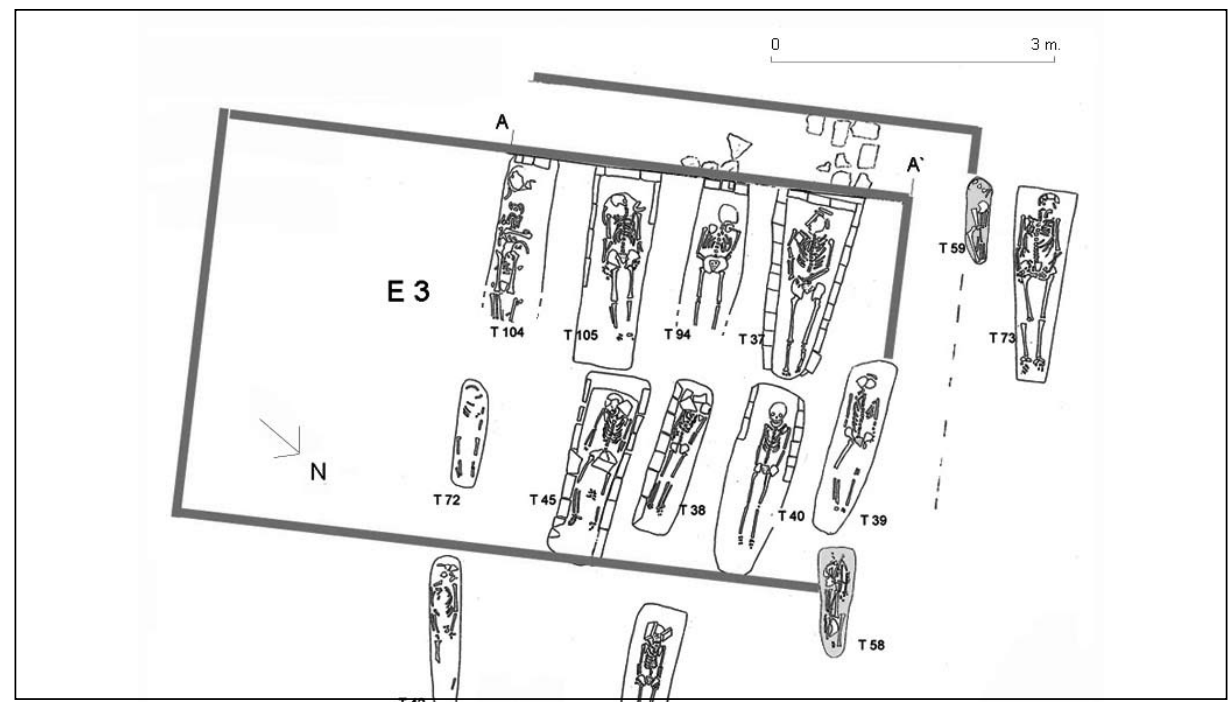

Fig. 8. Planta de la Estructura 3 y enterramientos asociados. 


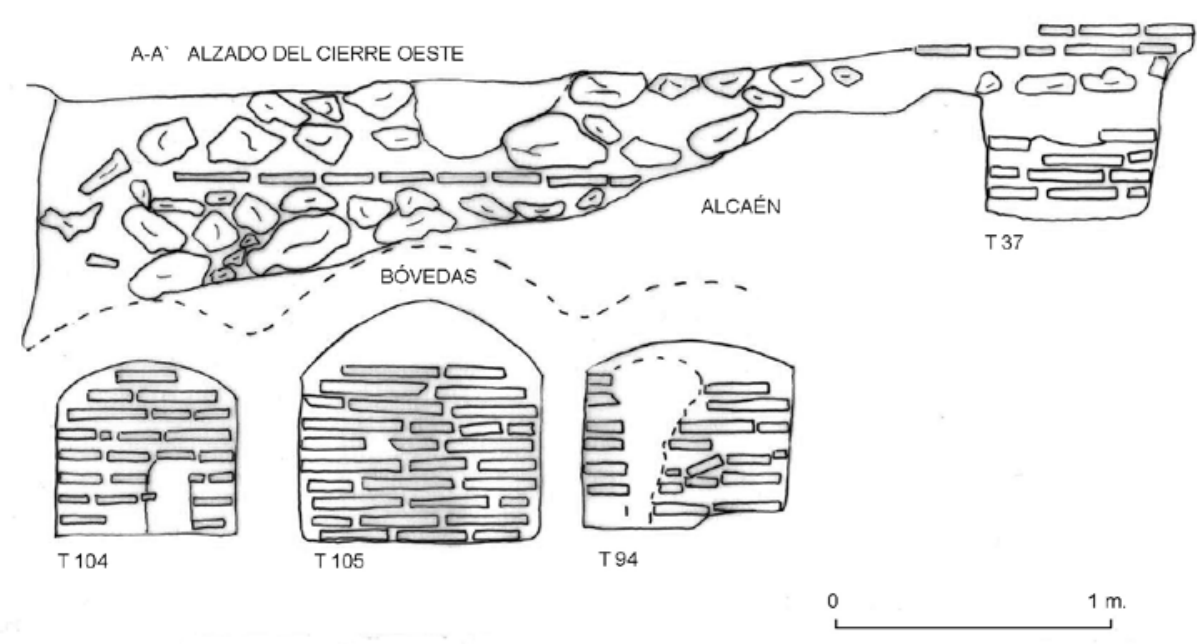

Fig. 9. Alzado del muro de cierre oeste de la Estructura 3.

de todo el cementerio. Construidas a partir de una única fosa, se encuentran divididas en tres lucillos unidos de entre los que destaca el situado en medio, por su mayor volumen (Fig. 10). Como ocurre con el resto de las tumbas de la necrópolis, estas aparecen desprovistas de ajuar. El resto de las tumbas de la E3 se disponen en torno a ella, siendo todas de cubierta abovedada a excepción de un enterramiento infantil a los pies de la tumba 104.

Como ocurre con la estructura 1, esta se ha visto alterada con posterioridad por la excavación de otras fosas ajenas a ella. De entre todas ellas, las tumbas 58 y 59 son las más interesantes, al ser los únicos casos documentados en esta necrópolis de resumen de restos. Los huesos se encuentran apilados en sus fosas, y en uno de los casos con restos de madera y clavos, lo que hace pensar que se encontraban en un ataúd (tumba 58).

Posiblemente el caso más atípico de todos los estudiados en este cementerio es el de la tumba 76. En una fosa excavada en el alcaén, sin estructura arquitectónica asociada, aparecieron una serie de restos humanos carbonizados, en una pequeña mancha de ceniza que no superaba los $60 \mathrm{~cm}$ de largo por $40 \mathrm{~cm}$ de ancho. Estos restos pertenecen a un individuo, aunque sólo se conservan algunas costillas y pequeños fragmentos de hueso. En ese contexto han aparecido también algunos clavos y restos de madera, lo que indica que originariamente debían estar depositados en un pequeño ataúd. No ha sido posible hacer una interpretación de estos restos, desconociendo tanto 


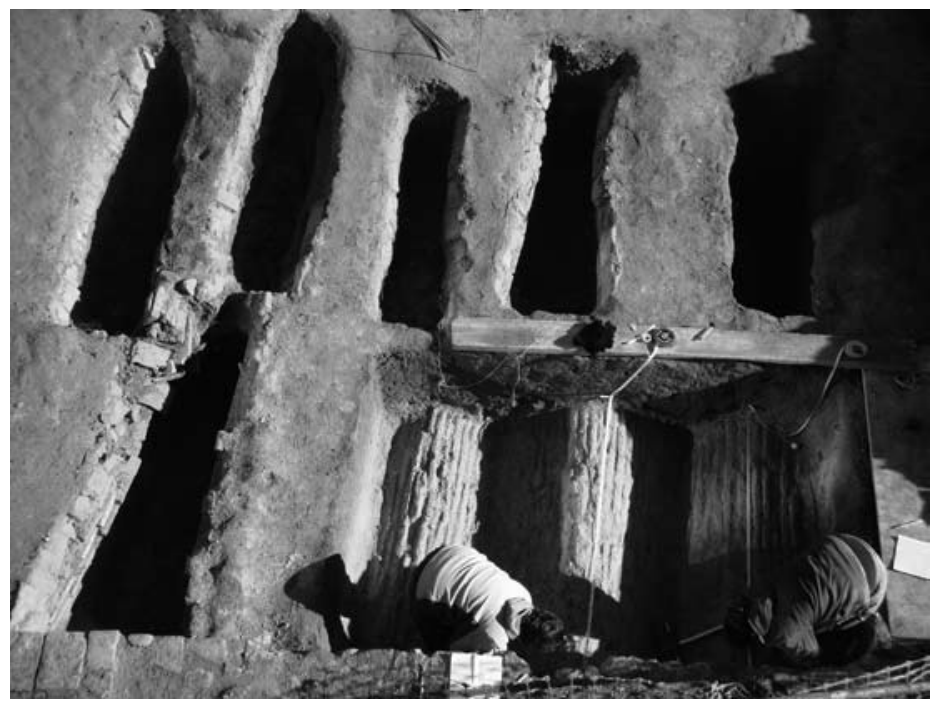

Fig. 10. Proceso de documentación de los lucillos 104, 105 y 94 de la E3.

las causas de la cremación de los mismos, como por qué se depositaron en este cementerio.

Además de estas estructuras, el cementerio cuenta con una enorme diversidad de enterramientos. Desde una gran fosa trapezoidal, que alberga un enterramiento doble a dos alturas desprovista de arquitectura asociada (tumba 63), a similares enterramientos, pero esta vez con estructura asociada (tumbas 27 y 28). Existen varios ejemplos de asociaciones madre-hijo, situándose el ataúd del neonato a los pies de la madre, que fácilmente se reconocen en la planta general del cementerio ${ }^{14}$. En un único caso se ha excavado la tumba de una mujer embarazada (tumba 86). Todos los grupos de edad se encuentran representados en el resto de tumbas ${ }^{15}$.

\section{Cronología y FASES DE ENTERRAMiEnTo.}

Como ya se ha mencionado anteriormente, el cementerio posee una estratigrafía horizontal, aunque se ha podido documentar un número reducido de tumbas asociadas tanto a las últimas fases de ocupación, como a las más antiguas. Sin poder precisar ni el momento de fundación ni su abandono, la tipología

\footnotetext{
${ }^{14}$ Las asociaciones de estas tumbas serían 26 y 25, 44 y 54, 24 y 65 y, por último, 23 y 21.

${ }^{15}$ Materiales arqueológicos y restos humanos se encuentran depositados en el Museo de Santa Cruz de Toledo; por desgracia sólo ha sido posible el estudio antropológico parcial de 35 individuos.
} 
constructiva de las estructuras asociadas a cada tumba indica que el cementerio posee un uso continuado durante la baja Edad Media. El estilo mudéjar que caracteriza estas construcciones sitúa sus orígenes en torno a los s. XI y XII. En el caso de que nos encontráramos ante una necrópolis judía, un posible límite cronológico de su uso sería 1492. No se puede descartar la posibilidad de que dejara de estar en funcionamiento antes de esta fecha. Por otro lado, el hallazgo de una moneda de Alfonso VII (1126-1157) asociada a un cráneo (tumba 101), nos indica que esa tumba no es anterior a la mitad del s. XII, pero podría ser incluso posterior, del siglo XIII (Fig. 11).
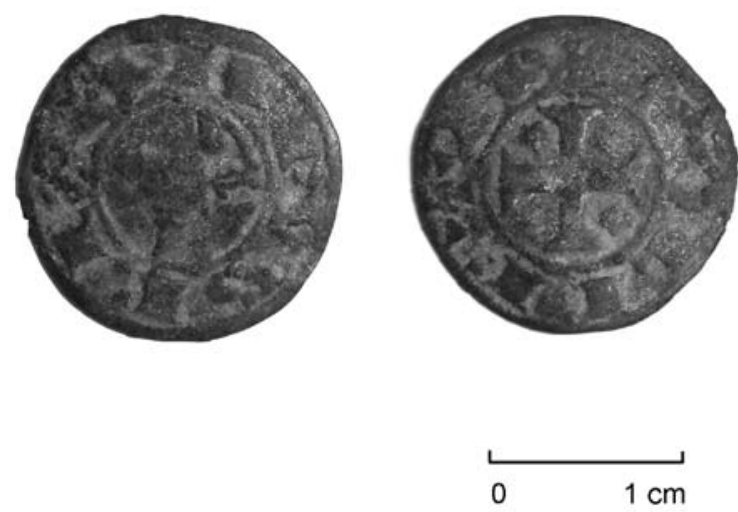

Fig. 11. Moneda de Alfonso VII (1126-1157), Tumba 101.

\section{DisCUSIÓN}

Los datos que se han expuesto en este artículo recogen las primeras consideraciones hechas del ritual funerario a partir de la evidencia arqueológica. Pese a que el registro material asociado al cementerio ha sido pobre, hay indicios arqueológicos que lo sitúan en el ámbito judío ${ }^{16}$. De una parte, la existencia de un patrón de enterramiento singular, desconocido hasta la fecha en Toledo. De otra, la existencia de otros elementos singulares, como la ordenación del cementerio, el respeto escrupuloso de los enterramientos anteriores, o el papel de las unidades familiares en el contexto funerario.

\footnotetext{
${ }^{16} \mathrm{El}$ cementerio no ha proporcionado evidencia epigráfica alguna que lo encuadre dentro de una de las tres religiones profesas en Toledo durante la Edad Media.
} 
Tienen bóveda de ladrillo o lucillo 55 de las 107 tumbas. Este tipo de cierre se relaciona directamente con el ataúd y no forma parte de la delimitación superficial de las tumbas. La construcción del lucillo se hace con posterioridad a la inhumación del cadáver. La gran profundidad de las fosas que se documentan en esta necrópolis imposibilita que la introducción del ataúd se hiciera por un lateral del lucillo. Además, esta profundidad debe ser considerada como fósil director a la hora de comparar rituales de enterramiento no sólo en Toledo sino en otras partes de España.

Desde un punto de vista macroespacial, la existencia de estructuras familiares y la ordenación de las tumbas y su disposición en filas vuelven a diferenciar este cementerio de los conocidos hasta la fecha en Toledo. En cuanto a la ocupación, aunque el cementerio posee una estratigrafía horizontal, se han identificado diferentes fases de enterramiento. Estas fases responden bien al uso continuado del espacio funerario a lo largo de los años, o bien a su agrupación en sectores relacionados con unidades familiares. Así, vemos que la mayoría de las tumbas que «invaden» enterramientos más antiguos se concentran en torno a las tres estructuras reconocidas. Además, se ha documentado arqueológicamente el cuidado para no alterar los enterramientos existentes. En este sentido, se ha constatado la reconstrucción de parte de una tumba dañada por la excavación de una fosa posterior, en la que el cráneo afectado se volvió a colocar en el mismo lugar, aunque a $20 \mathrm{~cm}$ por encima del esqueleto al que pertenecía (tumba 17). En otros dos casos hemos visto cómo las orientaciones de las tumbas se cambian drásticamente para no afectar tumbas más antiguas, $\mathrm{y}$, en uno, hasta se construye un lucillo de planta curva.

El contexto del cementerio excavado en uno de los sectores del Cerro de la Horca hay que situarlo cronológicamente en los primeros momentos de la Baja Edad Media. Es de esperar que futuros trabajos en zonas colindantes complementen la documentación extractada en este artículo. Hasta que tengamos nuevos datos, se puede concluir que el patrón de enterramiento del Cerro de La Horca no responde a nada conocido hasta la fecha en Toledo durante la Edad Media. Lejos de guardar similitudes con otras confesiones religiosas, tanto el ritual documentado como la cronología invitan a reflexionar si, por fin, se ha descubierto la localización de una de las necrópolis judías de Toledo.

Recibido: 20/02/2009

Aceptado: 15/04/2009 